\title{
Synergy analysis of agricultural economic cycle fluctuation based on ant colony algorithm
}

https://doi.org/10.1515/phys-2018-0119

Received Oct 15, 2018; accepted Nov 14, 2018

\begin{abstract}
The measurement of the agricultural economic cycle and its synergy analysis are of great significance for the formulation of agricultural macroeconomic policies. When the traditional methods are used to analyze the main factors affecting the synergy of agricultural economic cycle fluctuations, almost all of them use the correlation coefficient or the degree of agreement to express the degree of economic cycle synergy. It is impossible to accurately evaluate the degree of synergy of economic cycle fluctuations. To solve this problem, a quantitative calculation model of agricultural economic cycle synergy evaluation based on the ant colony algorithm is proposed. On the basis of the collected monthly data of agricultural economic operation indicators, a prosperity index that comprehensively reflects the development of agricultural economy is constructed. The law of economic prosperity cycle fluctuation is analyzed according to economic prosperity index, and HP filtering is utilized to decompose the trend fluctuations of the economic time series of various industries and obtain the fluctuation components. The ant colony algorithm is utilized to optimize the spearman correlation analysis method, and the correlation analysis of the wave components is carried out. The Fisher-z conversion is performed on the optimal Spearman correlation coefficient obtained by the optimization. The transformed results represent the degree of economic cycle synergy, considering the geographical distance, economic space spillover, fiscal policy synergy, regional income gap and geographical neighbors, a quantitative calculation model for agricultural economic cycle synergy evaluation is established. The results show that the agricultural economic cycle has a certain spatial correlation, and will expand the
\end{abstract}

\footnotetext{
*Corresponding Author: Shen Cheng: College of Economics and Management, China Agricultural University, Beijing 100083, China; Email: xhl180102@sina.com

Miguel A. López: Department of Mathematics, University of Castilla-La Mancha, Campus of Cuenca, 16071-Cuenca, Castilla-La Mancha, Spain; Email: mangel.lopez@uclm.es
}

agricultural economic fluctuations and form the cycle synergy through the periodic space overflow.

Keywords: Ant colony algorithm, agriculture, economic cycle fluctuation, synergy analysis, spearman correlation analysis method

PACS: 82.20.Wt, 88.05.Lg, 88.05.Qr

\section{Introduction}

The agricultural economic cycle has always been a key area of macroeconomic research. Since the 1990s, under the support of the theory of agricultural economic cycle, the empirical research on the agricultural economic cycle has made significant progress, mainly including the synergy analysis of the agricultural economic cycle and the analysis of the factors affecting the synergy of the agricultural economic cycle. To date, most scholars believe that the synergy of the agricultural economic cycle stems from a common economic cycle between regions [1]. Under the unified government policy, the fluctuations of the regional agricultural economic cycle should be similar, that is, have higher synergy [2]. However, it is generally believed that the synergy and difference of Chinese agricultural economic cycle coexist, and difference of the economic cycle has gradually expanded. How to narrow the differences and promote regional coordinated development has become the focus of attention of the current Chinese government. Therefore, it is of great significance to study the synergy of Chinese agricultural economic cycle and its influencing factors.

Foreign studies on the economic cycle started early, and Western scholars have also proposed various economic cycle fluctuation theories [3] and conducted empirical data research. In recent years, new progress has been made in new measurement methods and prediction models. As early as 1946, Burns and Mitchell found that the economic cycle showed obvious characteristics of industrial synergy. In 1981, Lucas's research once again confirmed the remarkable characteristics of industrial synergy from the perspective of correlation between industrial cy- 
cle fluctuations, and proved the overall random factor impact was an important factor for the formation of this synergy. Di Giorgio, Carlo studied the relationship between the economic cycle fluctuations between CEES and found that the economic cycle was more synergistic in the recession, while in the normal or high growth period, the economic cycle fluctuation between countries was weak.

With the development of Chinese economy, the improvement of market system and the opening of international trade, the characteristics of agricultural economic cycle fluctuations are becoming more and more significant. Although domestic research on the economic cycle is started relatively late, domestic scholars have paid more and more attention to the characteristics of Chinese agricultural economic cycle, and have made substantial progress in research methods and theories, and proposed theoretical explanations in line with Chinese national conditions. Regarding the analysis of agricultural economic fluctuation cycle and influencing factors, Zheng Shan et al. selected agricultural product price index, used HP filter decomposition model to divide the price of agricultural products, and analyzed the factors affecting the price fluctuation of agricultural products, and adopted factor analysis and the support vector machine autoregressive model for the empirical analysis [4]. Based on the annual data of the cost-benefit of agricultural products, Tao Yuan et al. selected the variables of the net income per unit area, the material per unit area and the selling price per unit product on the basis of descriptive analysis of the fluctuation characteristics of agricultural product cost and income. By constructing a VAR model and using impulse response functions and variance decomposition to analyze the influencing factors of agricultural product returns [5].

The above methods can not accurately evaluate the degree of synergy of economic cycle fluctuations. In response to the above problems, the agricultural economy has been innovatively researched, mainly in the following aspects:

- Exploring the transmission law of international economic cycle and agricultural economic fluctuations, and providing an analysis path for the investigation of economic fluctuation characteristics.

- Selecting the indicators that describe the operational status of the agricultural economy, using the prosperity index method to calculate a consistent climate synthesis index that comprehensively reflects the development of the agricultural economy.
- Adjusting agricultural product sales data, eliminating the influence of irregular factors and obtaining a time series containing trends and fluctuations.

Fisher-z conversion is performed on the optimal Spearman correlation coefficient, and the converted results are used to describe the synergy degree of economic cycle, and a quantitative calculation model for the agricultural economic cycle synergy estimation is further constructed.

\section{Materials and methods}

\subsection{Transmission mechanism of economic cycle synergy trade}

The coordinated fluctuation of the agricultural economic cycle is a phenomenon of economic cycle fluctuation. The theoretical explanation of this phenomenon should return to the theory explanation of economic cycle fluctuation mechanism. It is believed that the coordinated fluctuation of Chinese agricultural economic cycle is the internal transmission mechanism of the agricultural economy and the conduction to the economy. Cyclic fluctuations produce the result of an external impact mechanism. Exploring the transmission law of the international economic cycle and agricultural economic fluctuations is of great significance for further analysis of the coordinated fluctuations for the agricultural economic cycle [6].

\subsection{Intermediate product production}

In each country, $n=H, F$, a continuous monopolistic competitor employs all of the labor supply $L_{n e}$ in the country to produce intermediate goods $j$, where $N_{n t}$ represents the set of intermediate products available. Total Factor Labor Productivity (TFP) is described as $Z_{n t}$, indicating the efficiency of labor per unit of domestic labor, following the $A R(I)$ process:

$$
\log \left(Z_{n t}\right)=\rho_{n} \log \left(Z_{n, i-1}\right)
$$

where, $\rho_{n} \in(0,1)$.

The heterogeneity of the agricultural industry is reflected in the differences in production techniques expressed in terms of relative productivity $z$. A domestic agricultural enterprise with a relative productivity of $z$ employs 1 unit of labor to produce $Z_{n t} z$ units of output. The unit cost of production is given as $\omega_{n t} / Z_{n t} z$, where $\omega_{n t}=$ 
$W_{n t} / P_{n t}$ is the relative real wage, $W_{n t}$ and $P_{n t}$ are the nominal wage and price indices of country $n[7]$.

Intermediate product manufacturers can serve both domestic and foreign markets. Two types of export costs are introduced: the transportation cost of agricultural products $\tau_{t} \geq 1$, which mainly affects the margin of trade depth, and the fixed entry cost $f_{X, t}$ measured by effective labor units mainly affects the margin of trade. The fixed cost expressed in kind is paid separately in each period, and the fixed cost of export as a trade barrier mainly affects the margin of trade.

In countries of $n=H, F$, the demand function of the final producer faced by all intermediate production enterprises is given, so a price is added to the reaction marginal cost. The transportation costs that the products need to pay for shipment to foreign markets $\tau_{t}$ divide the domestic and international markets, and the prices of the two countries are different. $p_{n, t}^{D}$ and $p_{n, t}^{D}$ represent the domestic sales price and export price of the agricultural products of $n$ countries, respectively. The true price relative to the target market nominal price index is expressed as:

$$
\begin{aligned}
& p_{n, t}^{D}=\frac{\theta}{\theta-1} \frac{\omega_{n t}}{Z_{t} z} \text { and } \\
& Q_{t}^{-1}=\frac{\theta}{\theta-1} \frac{\omega_{n t}}{Z_{t} z} \tau_{t}
\end{aligned}
$$

where $Q_{t}$ is the real exchange rate and $\frac{\theta}{\theta-1}$ is the constant addition.

Due to the fixed export costs, enterprises with low productivity $z$ may decide not to export at any time. The enterprise breaks down its total profit $\pi_{n t}$ into domestic market sales profit $\pi_{n t}^{D}$ and potential foreign export profits. The total profit of agricultural products in the period $t$ is:

$$
\pi_{n t}=\pi_{n t}^{D}+\pi_{n t}^{X}
$$

In each period, $n$ countries have $N_{n t}^{D}$ domestic enterprises for production. Among these enterprises, $N_{n t}^{X}=$ $\left(1-G\left(z_{n, t}^{X}\right)\right) N_{n t}^{D}$ enterprises export agricultural products to foreign markets. As long as the productivity level of the enterprise is higher than the critical productivity level $z_{n t}^{X}=\inf \left\{z: \pi_{n t}^{X}(z)>0\right\}$, these enterprises will continue to export.

\subsection{Final product production}

In countries of $n=H, F$, a fully competitive enterprise uses capital $K_{n t}$ and a collection of tradable intermediate products at home and abroad, which is the material capital $M_{n t}^{\alpha}$, and generating a non-tradeable final product

$$
Y_{n t}=K_{n t}^{1-\alpha} M_{n t}^{\alpha}
$$

Intermediate products are combined according to the CES production function to generate physical capital:

$$
M_{n t}=\left(\int_{j=0}^{N_{n t}} y_{n j t} \theta d j\right)^{\theta}
$$

where $\theta>1$ is the symmetry alternative elasticity between the intermediates. The CES production function introduces diversity preferences: when expenditure $y_{n j t}$ remains constant, the larger the number $N_{n t}$ of species employed, corresponds to an increase in productivity levels.

The final product manufacturer chooses $y_{n j t}$ to maximize profits:

$$
\Pi_{n t}=P_{n t} Y_{n t}-R_{n t}^{k} K_{n t}-\int_{j=0}^{N_{n t}} p_{n j t} y_{n j t} d j
$$

where $P_{n t}$ is the final product price index and is expressed as:

$$
\begin{gathered}
P_{n t}=\left(\frac{R_{n t}^{k}}{1-\alpha}\right)\left(\frac{P_{n t}^{M}}{\alpha}\right)^{\alpha} \\
(1-\alpha) \frac{P_{n t} Y_{n t}}{K_{n t}}=R_{n t}^{k} \\
\alpha \frac{P_{n t} Y_{n t}}{M_{n t}}=P_{t}^{M}
\end{gathered}
$$

By merging the final product producer's demand for each intermediate $y_{n j t}$, then:

$$
y_{n j t}=\alpha^{\theta}\left(\frac{p_{n j t}}{P_{n t}}\right)^{-\theta}\left(\frac{Y_{n t}}{M_{n t}}\right)^{\theta} M_{n t}
$$

\subsection{Family department}

In countries of $n=H, F$, a representative household sector into:

$$
\begin{aligned}
P_{n t} C_{n t}+I_{n t} & =W_{n t} L_{n t}+\Pi_{n t}^{T}+R_{n t}^{k} K_{n t}+R_{n t} B_{n t} \\
& -B_{n, j+1}
\end{aligned}
$$

The productivity assumption assumes that the lower limit is the $z_{\min }$ Pareto distribution and the shape parameter is $k>\theta-1$. Based on the above assumptions, the average production productivity threshold for domestic production and exports is obtained:

$$
\tilde{z}_{n}^{D}=v z_{\min }
$$

$$
\tilde{z}_{n}^{X}=v z_{n t}^{X}
$$


where, $v=\left[\frac{k}{k-(\theta-1)}\right]^{\frac{1}{\theta-1}}$.

The number consumes end products, provides labor and leases capital to intermediate producers or for savings. The family department maximizes the expected utility function of a lifetime:

$$
U_{t}=E_{t} \sum_{s=t}^{\infty} \beta^{s}\left(\log \left(C_{n t}\right)-\frac{L_{n s}^{\psi+1}}{\psi+1}\right)
$$

The budget constraints faced are:

$$
\begin{aligned}
P_{n t} C_{n t}+I_{n t} & =W_{n t} L_{n t}+\Pi_{n t}^{T}+R_{n t}^{k} K_{n t}+R_{n t} B_{n t} \\
& -B_{n, t+1}+\omega_{n t}
\end{aligned}
$$

where $C_{n t}$ is consumption, $\beta$ is subjective discount factor, $\psi$ is labor supply elasticity, $P_{n t}$ is price index, $I_{n t}$ is nominal investment, $\omega_{n t}$ is wage, $\Pi_{n t}^{T}$ is the total profit of all enterprises in $n$ countries, $B_{n t}$ is family sector in period of $t-1$ to provide the total amount of loans that can be repaid in the period $t, R_{n t}^{k}$ is the risk-free probability, $r$ is the rent price of capital, and $K_{n t}$ is the capital supply obtained as follows:

$$
K_{n t}=(1-\delta) K_{n, t-1}+I_{n t} / P_{n t}
$$

where $\delta$ is the capital depreciation rate. The decisionmaking problem in the household sector is to choose consumption, labor attacks, and capital and maximize the utility of formula (14) under the constraints of formula (15).

There are an unlimited number of potential entrants in each period. The entrant is forward-looking and maximizes his profit $\pi_{n t}(z)=\pi_{n t}^{D}(z)+\pi_{n t}^{X}(z)$. All profits are expressed in terms of the number of final products under actual conditions.

$$
\pi_{n t}^{D}(z)=\frac{\alpha^{\theta}}{\theta}\left(p_{n t}^{D}(z)\right)^{1-\theta}\left(\frac{Y_{n t}}{M_{n t}}\right)^{\theta} M_{n t}
$$

If the enterprise $z$ exports, there are:

$$
\pi_{n t}^{X}(z)=\frac{\alpha^{\theta} Q_{t}}{\theta}\left(p_{n t}^{X}(z)\right)^{1-\theta}\left(\frac{Y_{n t}}{M_{n t}}\right)^{\theta} M_{n t}-\omega_{n t} f_{X t} / Z_{n t}
$$

Set average productivity levels and generalize all the information about the productivity distribution associated with macroeconomic variables, then:

$$
\tilde{z}_{D}=\left[\int_{-\min }^{\infty} z^{\theta-1} d G(z)\right]^{1 /(\theta-1)}
$$

The expected corporate value after the entry of the entrant is described by the discounted value of the expected profit stream:

$$
\tilde{v}_{n t}=E_{t} \sum_{s=t+1}^{\infty}[\beta(1-\delta)]^{s-t} \tilde{d_{n s}}
$$

New entrants enter the market until the average corporate value equals the entry cost. The free entry conditions are:

$$
\tilde{v}_{n t}=\omega_{n t} f_{E, t} / Z_{n t} .
$$

Assume that the entrant during the period of $t$ begins production in the period of $t+1$. The number of domestically produced varieties is:

$$
N_{n t}^{D}=(1-\delta)\left(N_{n, t-1}^{d}+N_{n, t-1}^{E}\right)
$$

The budget constraint is transformed of export intermediates is:

$$
\frac{N_{n t}^{X}}{N_{n t}^{D}}=z_{\min }^{k}\left(\tilde{z}_{n t}^{X}\right)^{-k}\left(\frac{k}{k-(\theta-1)}\right)^{\frac{k}{\theta-1}}
$$

It is worth noting that when other conditions remain unchanged, as the number of export varieties increases, the more domestic manufacturers enter, the lower the average productivity threshold of manufacturers' exports.

Assuming that the financial sector is closed, trade is balanced in all phases, and the total exports of $n$ countries are equal to the total imports, that is, the balance of trade is balanced:

$$
\begin{aligned}
& Q_{t} N_{H, t}^{-X}\left(\tilde{\rho}_{H, t}^{-X}\right)^{1-\theta}\left(\frac{Y_{F t}}{M_{F t}}\right)^{\theta} M_{F t} \\
& =N_{H, t}^{X}\left(\tilde{\rho}_{F t}^{X}\right)^{1-\theta}\left(\frac{Y_{H t}}{M_{H t}}\right)^{\theta} M_{H t}
\end{aligned}
$$

The final product of each country is either used for consumption or for investment, and the market clearing conditions are:

$$
Y_{n t}=C_{n t}+I_{n t}
$$

The demand for domestic and foreign varieties is equal to its supply:

$$
\tilde{y}_{H t}=y_{H t}^{\tilde{D}}+y_{H t}^{\tilde{X}}
$$

The balance of foreign intermediates is similar to the domestic situation. For countries of $n=H, F$, the general equilibrium of the symmetry of the economy is set as: exogenous random sequence $\left\{Z_{n t}\right\}$, initial vector $\left\{Z_{n 0}, N_{n 0}^{D}, K_{n 0}\right\}$, a set of different parameters $\left\{p_{n}\right\}$ for two countries, average price and wage sequence $\left\{Q_{t}, P_{n t}, R_{n t}, \omega_{n t}\right\}_{t=0}^{\infty}$, a set of intermediate price $\left\{\tilde{p}_{n t}^{D}, \tilde{p}_{n t}^{X}\right\}_{t=0}^{\infty}$, one group total sequence $\left\{Y_{n t}, \tilde{y}_{n t}, I_{n t}\right\}$, intermediate product yield sequence $\left\{Y_{n t}, \tilde{y}_{n t}, I_{n t}\right\}$, intermediate product quantity sequence $\left\{y_{n t}^{D}, y_{n t}^{X}\right\}_{t=0}^{\infty}$, domestic production and export average productivity threshold $\left\{z_{n, t}^{X}, z_{n, t}^{D}\right\}_{t=0}^{\infty}$, profit and enterprise value sequence $\left\{\Pi_{n t}, \tilde{d}_{n t}, \tilde{v}_{n t}\right\}_{t=0}^{\infty}$, capital accumulation rule $\left\{N_{n t}^{D}, N_{n t}^{X}, Z_{n, t+1}, K_{n t}\right\}_{t=0}^{\infty}$. 
It can be seen from formula (4) and formula (5) that production efficiency and total factor productivity (TFP) depend on the quantity of domestic and foreign intermediate products used to produce the final product. By averaging the firm variable (19), it can be found that the TFP in the model consists of two parts: the total productivity impact determines the amount of the exogenous part and the intermediate product used to produce the final product and the average productivity of each intermediate product.

Based on the above process, the transmission mechanism of the coordination of agricultural economic cycle fluctuations is given:

$$
\begin{aligned}
& \operatorname{TFP}_{n t} \\
& \left.=z_{n t}\left\{\frac{1}{N_{n t}^{D}+N_{n t}^{X}}\left\{N_{n t}^{D}\left(\tilde{z}_{n t}^{D}\right)^{\theta-1}+N_{n, t}^{X}\left(Z_{n, t} / z_{n, t}^{X} \tau / Q\right)\right)\right\}\right\}
\end{aligned}
$$

A positive productivity shock in the home country creates a demand-supply spillover effect. Through this effect, the demand for foreign intermediate goods by domestic final product producers will increase, and the output of foreign economies will increase. This is also a channel of communication presented in the traditional economic cycle model.

\subsection{Research on coordination characteristics of economic cycle based on prosperity index}

Through the fluctuation range of the economy, the characteristics of the industry cycle fluctuations are studied, and the composite index method that can specifically describe the fluctuation range of the economic climate of the industry which is used to calculate the industry sentiment index.

To find the symmetrical rate of change of the indicator and standardize it.

Let indicator $C_{i}(t)$ as the $i$-th indicator and $i=$ $1,2, \cdots, K$ as the indicator number. The ratio sequence is chosen, and the rate of change $C_{i}(t)$ is taken as the $Y_{i}(t)$ first order difference:

$$
C i(t)=Y_{i}(t)-Y_{i}(t-1)
$$

In order to prevent the index of abnormality of the rate of change from gaining a dominant position in the composite index, it is necessary to standardize the rate of symmetrical change of each index so that the average absolute value is 1 . The normalization factors are given below:

$$
A i=\sum_{t=2}^{T} \frac{|C i(t)|}{T-1}
$$

Standardizing $C_{i}(t)$ with $A i$ to obtain a standardized rate of change $\operatorname{Si}(t)$ :

$$
\operatorname{Si}(t)=\frac{\operatorname{Ci}(t)}{A i}
$$

The average rate of change of the consistent indicator group $R(t)$ :

$$
R(t)=\frac{\sum_{i=1}^{k} S i(t) \cdot w_{i}}{\sum_{i=1}^{k} w_{i}}
$$

To calculate the initial consistent composite index, let, then agree on the composite index:

$$
I(t)=I(t-1)+R(t)
$$

Only the consensus synthesis index is required, and there is no need to adjust the trend for the leading and lagging indicator groups to obtain the composite index with the base year of 100 :

$$
C I(t)=\frac{I(t)}{\bar{I}} \times 100
$$

where $\bar{I}$ is the average of the base year and 2018 is the base year.

The cumulative annual growth rate of agricultural added value, the cumulative year-on-year growth rate of main business income, and the cumulative year-on-year growth rate of fixed asset investment were the prosperous indicators, and the consensus synthesis indexes of agricultural and agricultural sub-sectors were established [8].

\subsection{Descriptive statistical analysis of industry consensus synthetic index}

In order to further empirically test the synergy of Chinese agricultural economic cycle fluctuations, study the law of Chinese agricultural economic cycle fluctuations, and analyze the statistics of economic climate cycle fluctuations by describing the statistics of agricultural economic sentiment consistent synthetic index trend fluctuation time series. The wave component and trend component are separated to eliminate the impact of common trends among various industries on the analysis of fluctuation correlation, and to better discover the law of economic fluctuation. The HP filtering method, which is widely used in the world to decompose the economic time series trend, is selected to decompose the trend fluctuations of the economic time series of various industries to obtain the wave components, and perform spearman correlation analysis on the wave components to verify the fluctuation of various industries. 
Based on modern economic growth theory, the economic cycle of an economy can be seen as consisting of long-term trend components and short-term fluctuations. Before conducting the study of the volatility characteristics of the economic cycle, it is necessary to determine the separation of the long-term trend components to obtain the actual economic cycle fluctuation components.

Let the economic time series $Y=\left\{y_{1}, y_{2}, \cdots, y_{n}\right\}$, the long-term trend term is $Y^{t}=\left\{y_{1}^{t}, y_{2}^{t}, \cdots, y_{n}^{t}\right\}$, and is the sample length of the time series. The "smooth" feature of long-term trend components allows the extraction of trend component problems from time series to be defined as the solution variance minimum:

$$
\operatorname{MinF}=\sum_{i=1}^{n}\left\{\left(y_{i}-y_{i}^{t}\right)^{2}+\lambda\left[c(L) y_{i}^{t}\right]^{2}\right\}
$$

where $\lambda>0$ is the smoothing parameter, indicating the weight of the decomposition trend component, and $c(L)$ is the lag operator polynomial, the expression is:

$$
c(L)=\left(L^{-1}-1\right)-(1-L)
$$

Bring formula (35) into (34), the minimum function is:

$$
\begin{aligned}
& \text { MinF } \\
& =\sum_{i=1}^{n}\left\{\left(y_{i}-y_{i}^{t}\right)^{2}+\lambda \sum_{i=1}^{n}\left[\left(y_{i}^{t}-y_{i-1}^{t}\right)-\left(y_{i}^{t}-y_{i-2}^{t}\right)\right]^{2}\right\}
\end{aligned}
$$

where $\sum_{i=1}^{n}\left(y_{i}-y_{i}^{t}\right)^{2}$ is a measure of sequence fluctuations and $\left.\lambda \sum_{i=1}^{n}\left[\left(y_{i}^{t}-y_{i-1}^{t}\right)-\left(y_{i}^{t}-y_{i-2}^{t}\right)\right]^{2}\right\}$ is a measure of longterm trend smoothness. Here you need to choose the appropriate $\lambda$ value, different $\lambda$ values determine the different period fluctuations and smoothness, which has a direct impact on the accuracy of the results. The value of $\lambda=100$ usually takes $\lambda=1600$ when the time series is annual data; for monthly data, take $\lambda=15200$.

\subsection{Analysis of the synergistic characteristics of economic cycle fluctuations}

Before the analysis of the synergistic characteristics of the economic cycle of the agricultural industry, the statistical analysis of the separated wave components is carried out, and the Spearman correlation coefficient between the sequences is selected as the correlation index. The Spearman method was chosen because it provides a better measure of the correlation between non-normally distributed time series and nonlinear relationships. The Spearman correlation coefficient is calculated as:

$$
r_{S}=\frac{\sum_{i=1}^{n}\left(R_{i}-\bar{R}\right)\left(Q_{i}-\bar{Q}\right)}{\sqrt{\sum_{i=1}^{n}\left(R_{i}-\bar{R}\right)^{2}} \sqrt{\sum_{i=1}^{n}\left(Q_{i}-\bar{Q}\right)^{2}}}
$$

where $R_{i}$ and $Q_{i}$ are the ranks of two random variables $x_{i}$ and $y_{i}$ in their corresponding vectors $\left(x_{1}, \cdots, x_{n}\right)$ and $\left(y_{1}, \cdots, y_{n}\right)$, respectively.

The Spearman correlation analysis method has some limitations. The method requires the variable to conform to a normal distribution, and is not credible if the condition is not satisfied. To solve this problem, the ant colony algorithm [9] is introduced, and the solution of the wave correlation coefficient can be regarded as the optimization process of the following function:

$$
\begin{aligned}
& \min \left\{\frac{1}{p^{\prime}} \sum_{j=1}^{p^{\prime}} C_{j, N_{j}}^{2}\right\} \\
& \text { s.t. }\left\{\begin{array}{l}
U_{i} \leq U_{i, 0-\sigma_{i} \Omega} \\
C_{i, N_{i}}^{2} \leq C_{i, N_{i}, \sigma_{i}}^{2}
\end{array}\right.
\end{aligned}
$$

This is a constrained minimum problem whose domain is a contiguous domain, namely:

The objective function is:

$$
f(k)=\left\{\frac{1}{p} \sum_{j=1}^{p} C_{j, N_{j}}^{2}\right\}
$$

The restrictions are:

$$
\left\{\begin{array}{l}
U_{i}(k) \leq U_{i,\left(1-\alpha_{i} / 2\right)} \\
C_{i, N_{i}}^{2}(k) \leq C_{i, N_{i}, \alpha_{i}}^{2} .
\end{array}\right.
$$

The goal is to find a set of optimal values within the normal range of the fluctuation correlation coefficient so that the minimum value is obtained under the target value sub-constraint.

Randomly virtualized $\dot{N}$ individual workers in the feasible solution range (take $\dot{N} \dot{k}$ values randomly within the range of $\dot{k}$, and set the evaluation function value to be the corresponding target value $f_{o}$. The transfer probability of each ant (ie from the definition of the probability that the space of the ant $\xi$ is transferred to the space where the ant $\xi$ is located is different from other combinations of the optimized path class problem, and is set as follows:

$$
p_{\xi \zeta}=\frac{\tau_{\zeta}^{\alpha} \eta_{\xi \zeta}^{\beta}}{\sum_{\dot{m}} \tau_{\zeta}^{\alpha} \eta_{\zeta \zeta}^{\beta}}
$$


among which, the track strength $\tau_{\zeta \xi}$ is converted to $\tau_{\zeta}$, which represents the pheromone size of the ant $\zeta$, and can also be referred to as the field attraction intensity of the ant $\zeta$. The heuristic pheromone $\eta_{\xi \zeta}=f_{\xi}-f_{\zeta}$ represents the difference value of the objective function. The parameters $\alpha$ and $\beta$ are used to describe the relative influence of pheromones and heuristic pheromones, respectively.

When the ants in the population have constructed the path, the pheromone on each side will be updated. All pheromones reduce the size of a constant factor or the retention strength of a pheromone. Add pheromones to the side where the ants pass. The evaporation of pheromones or the retention of pheromones is performed according to the following formula:

$$
\tau_{\zeta}^{\prime}=(1-\dot{\rho}) \tau_{\zeta}
$$

where $\dot{\rho}$ is called the vegetative evaporation rate and $0<$ $\dot{\rho} \leq 1$. The role of the parameter $\dot{\rho}$ is to avoid the infinite accumulation of pheromones. If an edge is not selected by any other ant, the pheromone on the edge will be decremented exponentially. After the pheromone evaporation step, all ant colonies release pheromones on the edges they pass, and the pheromone intensity update formula is:

$$
\tau_{\zeta}^{\text {new }}=\dot{\rho} \tau_{\zeta}^{\text {old }}+\sum_{\dot{m}} \Delta \tau_{\zeta}^{\dot{m}}
$$

\subsection{Quantitative calculation model for cooperative estimation}

The Fisher-z conversion is performed on the optimal Spearman correlation coefficient. The transformed results represent the degree of economic cycle synergy, and consider the geographical distance, economic space spillover, fiscal policy synergy, regional income gap and geographical neighbors to construct a quantitative calculation model for agricultural economic cycle synergy evaluation.

The economic cycle synergy degree $Z_{\phi \varphi}$ is based on the Spearman correlation coefficient. The specific transformation formula is as follows:

$$
\begin{aligned}
& Z_{\phi \varphi}=\frac{1}{2}\left(\frac{1+\rho_{\phi \varphi}}{1-\rho_{\phi \varphi}}\right) \\
& Z_{\phi \varphi}=\frac{1}{2}\left(\frac{1+I_{\phi \varphi}}{1-I_{\phi \varphi}}\right)
\end{aligned}
$$

among which, the correlation coefficient $\rho_{\phi \varphi}$ is calculated from the periodic component of the actual output; the degree of coincidence $I_{\phi \varphi}$ is expressed according to the proportion of the economic period between the regions in the same period.
The geographical factor $D_{\phi \varphi}$ represents the geographical distance between the $\phi$ region and the $\varphi$ region. The geographical distance affects the flow cost of agricultural products and factors, changes the trade flow between regions, and affects the degree of synergy in the economic cycle. Introducing geographical distance factors into the model, it is generally believed that the further the geographical distance between regions, the higher the trade cost required, and the lower the economic cycle synergy.

The economic scale $S_{\phi \varphi}$ will also cause changes in trade flows between regions, which in turn will affect the degree of synergy in the economic cycle [10]. The size of the economy should be introduced into the model. It is generally believed that the larger the size of the inter-regional economy, the greater the trade flows generated, and it is expected to increase the synergy of the economic cycle. The economic scale is the sum of the regional GDP between the two provinces. The specific calculation formula is as follows:

$$
S_{\phi \varphi}=\frac{1}{T} \sum_{t}\left(G D P_{\phi t}+G D P_{\varphi t}\right)
$$

where $S_{\phi \varphi}$ represents the economic size between the region $\phi$ and the region $\varphi, G D P_{\phi t}$ and $G D P_{\varphi t}$ are used to describe the regional GDP of the $\phi$ region and the region, respectively.

The fiscal policy coordination degree is $c_{\phi \varphi}$. To a certain extent, the formulation of national macroeconomic policies can "smooth" the fluctuations of the economic cycle and become the main factor for the coordinated impact of the inter-regional economic cycle. Therefore, the coordination degree of fiscal policy in macroeconomic policy is introduced into the model as an explanatory variable. Experts predict that the higher the inter-regional fiscal policy coordination, the more similar the economic cycle [11]. The coordination of financial and economic policies is represented by the gap between regional fiscal expenditures, and the calculation formula is as follows:

$$
c_{\phi \varphi}=\frac{1}{T} \sum_{t}\left(f_{\phi t}-f_{\varphi t}\right)
$$

among which, $c_{\phi \varphi}$ is used to describe the fiscal policy coordination degree between region $\phi$ and region $\varphi$, and $f_{\phi t}$ and $f_{\varphi t}$ respectively represent the proportion of provincial finances to the GDP of other regions.

The inter-regional income gap also affects trade flows between regions and thus the degree of economic cycle synergy [12], which is introduced into the model. It is expected that the widening income gap between regions will reduce the degree of synergy in the economic cycle. The income gap is set as the sum of the per capita disposable income between the two provinces divided by the per capita 
disposable income. The specific formula is:

$$
Y_{\phi \varphi}=\frac{\left|y_{\phi t}-y_{\varphi t}\right|}{y_{\phi t}+y_{\varphi t}} .
$$

where $Y_{\phi \varphi}$ represents the income gap between the regional $\phi$ and $\varphi$ regions, and $y_{\phi t}$ and $y_{\varphi t}$ represent the per capita disposable income of the $\phi$ and $\varphi$ regions, respectively.

The specialization of production will increase regional differences [13], affecting the synchronicity of the regional economic cycle, and the same factor is added to the model. The difference in industrial structure is constructed according to three industrial differences between provinces. The calculation formula is as follows:

$$
\operatorname{Sis}_{\phi \varphi}=\frac{1}{T} \sum_{t} \sum_{\chi=1}^{3}\left|S_{\phi t}^{k}-S_{\varphi t}^{k}\right|
$$

where $\operatorname{Sis}_{\phi \varphi}$ represents the industrial structure difference between the region and the region $\varphi$, and $S_{\phi t}^{k}$ and $S_{\varphi t}^{k}$ respectively represent the proportion of the industry in the $\phi$ and $\varphi$ regions, and $k=1,2$, and 3 represent the primary industry, the secondary industry, and Tertiary Industry.

Geographical proximity $B_{\phi \varphi}$, because the domestic goods and elements can flow freely, the geographically adjacent areas trade relatively close, naturally generate different trade flows, and thus affect the degree of economic cycle synchronization. Set the geographic proximity factor to a dummy variable, the neighboring provinces take a value of 1 , and the non-adjacent provinces take a value of 0.

In order to further determine the impact of different regions on the degree of synergy of the agricultural economic cycle [14], introduces dummy variables in the eastern, central and western regions. If the two regions are in the same region, the value is 1 , otherwise it is 0 .

Considering geographical distance, bilateral economic scale, fiscal policy synergy, regional income gap, geographical neighbors, economic space spillover, government expenditure cycle synergy, investment cycle synergy, international trade cycle synergy and other factors to construct quantitative calculation of agricultural economic cycle synergy estimation model, then:

$$
\begin{aligned}
\hat{Z}_{\phi \varphi} & =\beta_{0}+\beta_{1}\left(D_{\phi \varphi}\right)+\beta_{2}\left(S_{\phi \varphi}\right)+\beta_{3}\left(c_{\phi \varphi}\right) \\
& +\beta_{4}\left(Y_{\phi \varphi}\right)+\beta_{5}\left(\operatorname{Sis}_{\phi \varphi}\right)+\beta_{6}\left(B_{\phi \varphi}\right)+\sum_{k} \beta_{7}^{k} \text { Area }_{k} \\
& +\varepsilon_{\phi \varphi}
\end{aligned}
$$

where $Z_{\phi \varphi}$ is the explanatory variable, indicating the degree of synergy in the agricultural economic cycle, $D_{\phi \varphi}$ is the geographical distance variable, $S_{\phi \varphi}$ is the economic scale variable, $c_{\phi \varphi}$ is the fiscal coordination degree variable, $Y_{\phi \varphi}$ is the inter-regional income gap variable, $\operatorname{Sis}_{\phi \varphi}$ is the industrial structure difference variable, $B_{\phi \varphi}$ represents the geographical neighbor variable, and Area represents the regional dummy variable [15-21].

\section{Results}

In order to verify the comprehensive effectiveness of the quantitative calculation method based on ant colony algorithm for the evaluation of agricultural economic cycle fluctuations, a simulation experiment is needed. The simulation experiment environment is equipped with Inter Core i51.3GHz processor and $4 \mathrm{~GB}$ of Mac BookAir (2013Mid). The operating system is OS X10.9.4 and all simulation experiments were performed on MATLAB R2013a.

The HP filter cycle component maps of agricultural economic variables in various provinces of China are plotted, as shown in Figure 1. In Figure 1, the HP periodic component units produced are constant and are denoted by $\mathrm{C}$.

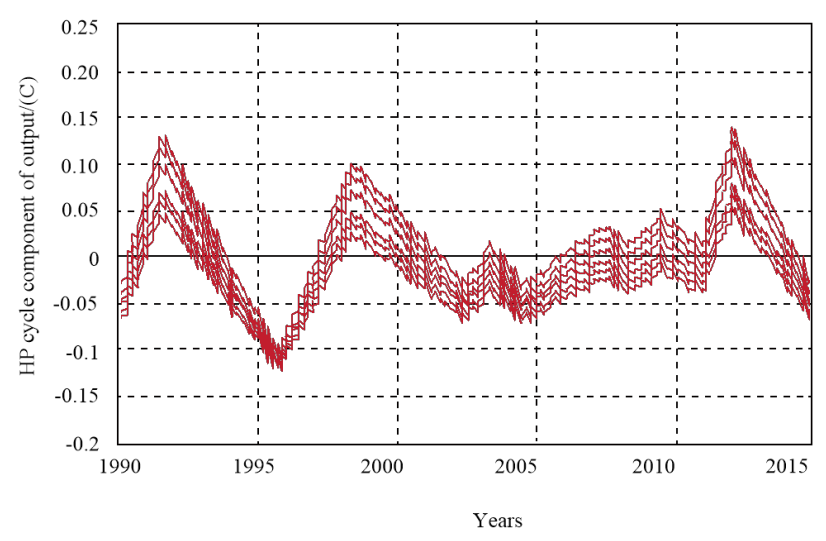

Figure 1: Province output cycle

As can been seen from Figure 1, before 2000, the agricultural economy of the provinces fluctuated greatly. The fluctuations in 2000-2010 tended to ease. After 2010, the degree of volatility increased, but it was still weaker than the late 1980s to 90 . The level of the mid-1990s. Since 1990, the degree of synergy between the inter-provincial economic cycles has increased. After 2000, economic fluctuations have become more consistent. Consistent with the research conclusion that the output growth rate cycle is used as a measure of the agricultural economic cycle, the domestic agricultural economic cycle appears to be mi- 
crowaved, and the inter-provincial economic cycle synergy tends to increase.

In addition, there are synergistic phenomena in the province's domestic trade, investment, government spending, total imports and total export cycles, as shown in Figures 2-6, but the degree of synergy is weaker than the economic cycle synergy. In Figures 2-6, the HP cycle component of domestic trade, the HP cycle component of investment, the HP cycle component of government expenditure, the HP cycle component of the import, and the HP cycle component of the export are all constant, denoted by C.

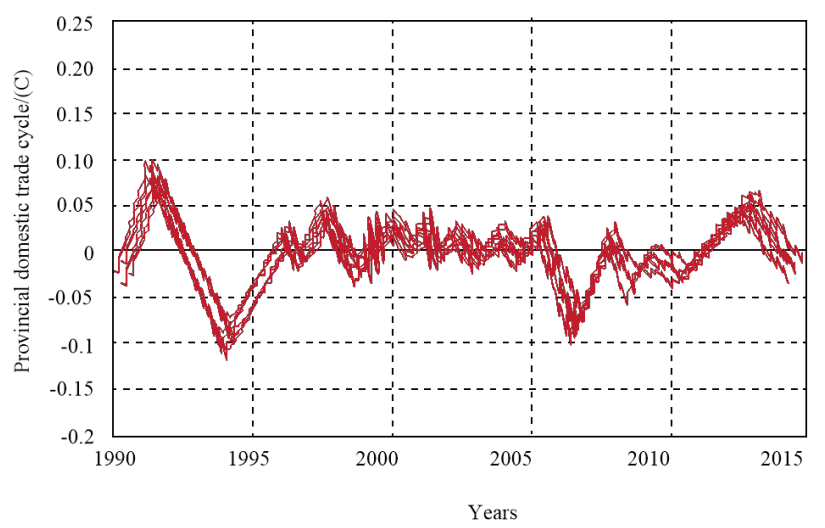

Figure 2: Province domestic trade cycle

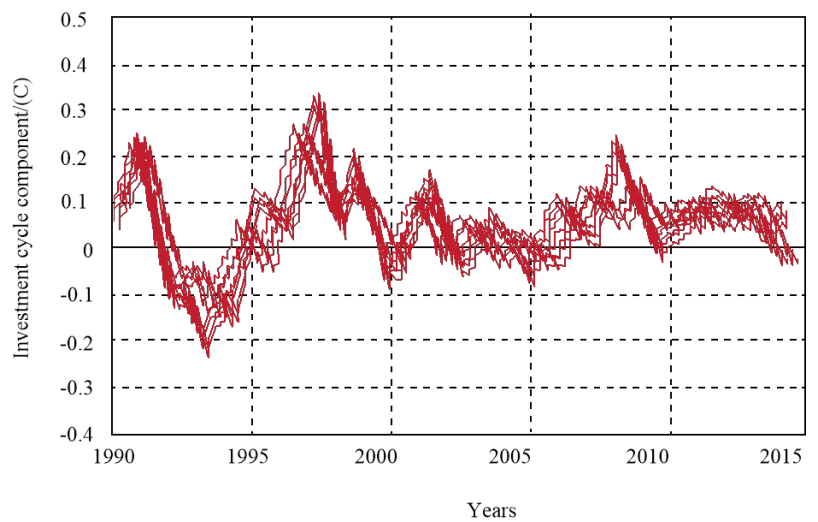

Figure 3: Province investment cycle

In order to reflect the trend of the correlation of agricultural economic cycle fluctuations, 8 years is selected as the time window width, and the fluctuation correlation coefficient of the 8-year moving average is calculated. As shown in Figure 7. The unit of the fluctuation correlation coefficient is a constant and is expressed by $\mathrm{C}$.

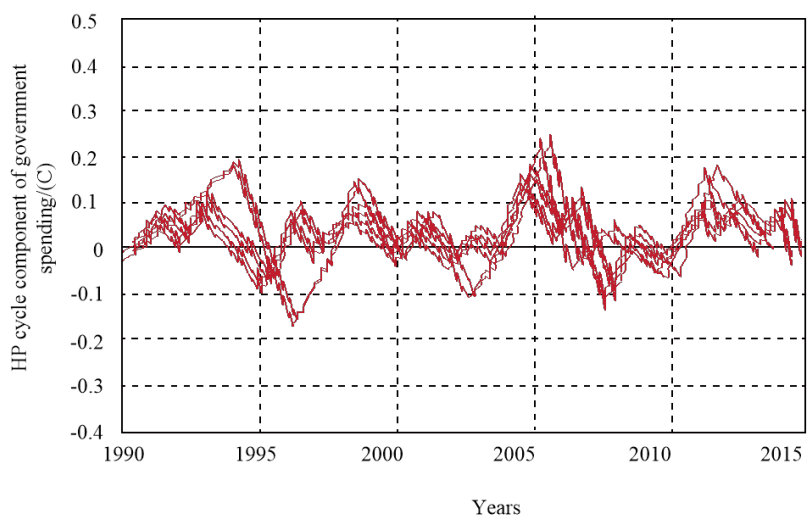

Figure 4: HP cycle components of government spending

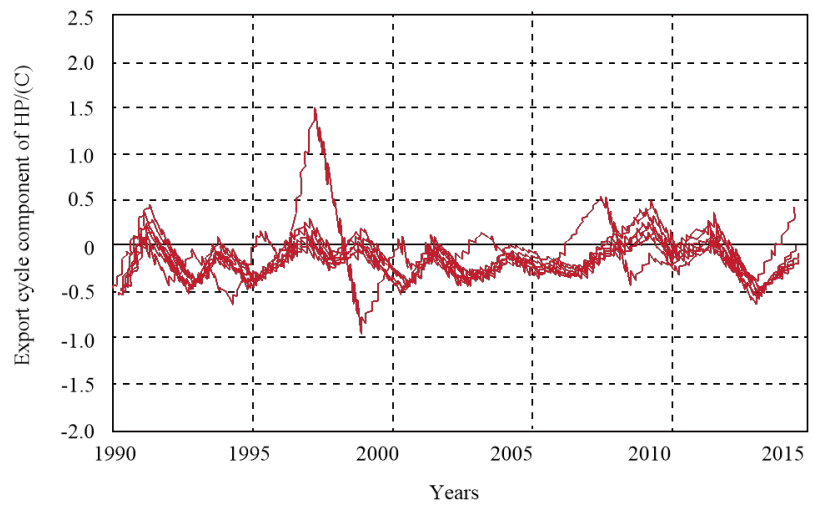

Figure 5: Province total import cycle

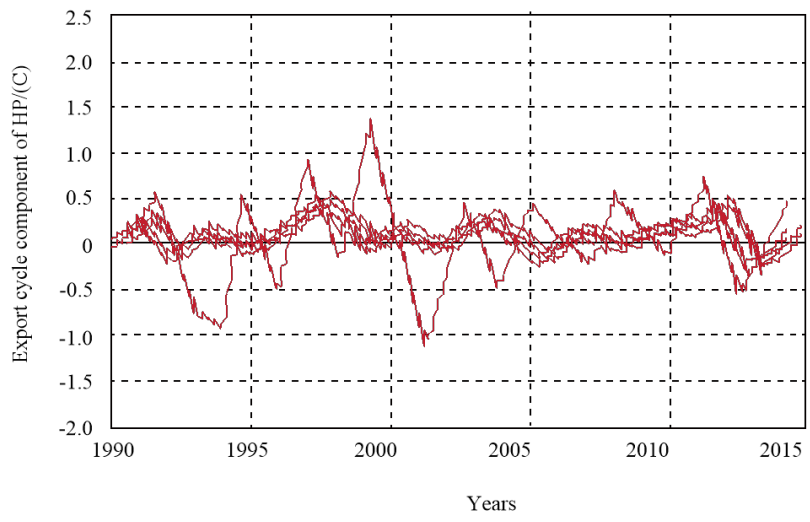

Figure 6: Province total export cycle

In order to verify the direct impact of cyclical space spillover on the economic cycle synergy, the economic spatial overflow is used as an explanatory variable to regress the periodic synergy index, and the data used to estimate the model is obtained. According to Figures 27 , the province's domestic trade, investment, government spending, import and export cycles also have different levels of synergy, while controlling the impact of the synergy 
Table 1: Estimated results

\begin{tabular}{lccc}
\hline Variables & $1990-2015$ & $1990-2010$ & $2010-2015$ \\
\hline Economic spatial spillover & $1.668^{\star \star \star}$ & $2.839^{\star \star \star}$ & $3.458^{\star}$ \\
& {$[2.85]$} & {$[4.25]$} & {$[1.78]$} \\
Government spending cycle synergy & $-0.105^{\star \star \star}$ & $-0.087^{\star \star}$ & -0.105 \\
& {$[-3.15]$} & {$[-2.02]$} & {$[-0.36]$} \\
Investment cycle synergy & $-0.115^{\star \star}$ & -0.064 & $-0.146^{\star}$ \\
& {$[-2.70]$} & {$[-2.02]$} & {$[-1.92]$} \\
International trade cycle synergy & 0.065 & 0.045 & $0.105^{\star \star}$ \\
& {$[1.65]$} & {$[0.95]$} & {$[2.05]$} \\
\hline
\end{tabular}

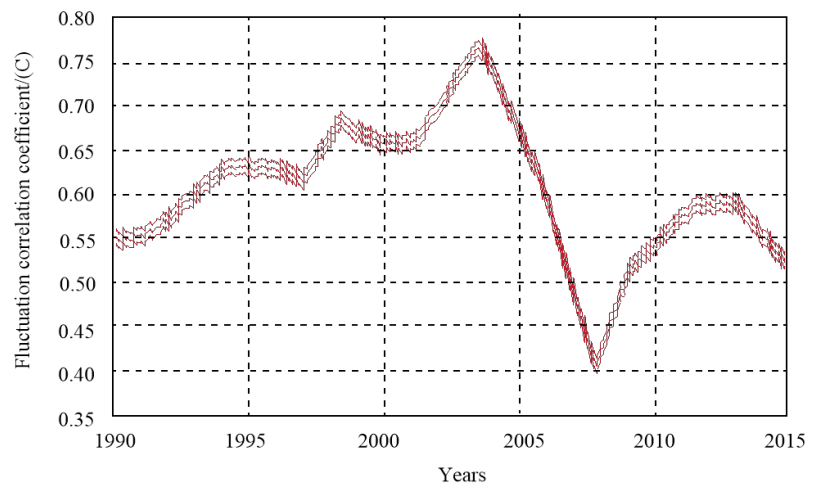

Figure 7: Average fluctuation correlation coefficient

index on the volatility of the agricultural economic cycle. The results of the agricultural economic cycle synergy estimation are shown in Table 1.

\section{Discussions}

The experimental results show that the correlation coefficient of economic cycle fluctuations increased slightly during the period 1990-2003. In 2003, the correlation coefficient of fluctuation began to decline. During this period, the overall spatial concentration of the agricultural economic cycle decreased significantly. It did not start to rise until 2007, but it was lower than that before 2003. In combination with Figure 1, when the aggregation degree of economic fluctuation space was high, the degree of economic fluctuations in the province was large; when the degree of spatial aggregation decreased, the magnitude of economic fluctuations also decreased. This phenomenon also indicated that geographically close provinces may amplify (or stabilize) economic fluctuations through space spillovers, forming a synergy in the agricultural economic cycle.
Economic space spillovers have a significant positive impact on the synergy of the agricultural economic cycle, and the degree of impact exceeds other explanatory variables. Prior to 2010, the impact of government spending cycle synergies, investment cycle synergies, and international trade cycle synergies on economic cycle synergies was not significant. After 2010, the impact of these factors on economic cycle synergies became significant. In particular, the impact of the synergy of the international trade cycle has become very high, which is related to the further integration of the Chinese economy into the world economic cycle. In addition, domestic investment is affected by many non-market factors, local governments have a strong control over a considerable portion of fixed-asset investment. After 2010, in addition to the increase in the contribution of the export cycle synergy to the economic cycle synergy, the impact of the import cycle synergy on the economic cycle synergy had also increased significantly. For a long time, Chinese agricultural import trade was dominated by imports of goods, and the proportion of capital goods and primary products was high, and the proportion of the two in total imports peaked in 2010 and 2015 respectively. This shows that the structure of imported products is closely related to the domestic economy. For provinces with similar industrial structure, the dual impact of foreign supply of imports and the specific industries in the country created a combined impact, which increased the correlation between the synergy of the import cycle and the economic cycle.

\section{Conclusions}

The spatial spillover of the agricultural economic cycle and the spatial spillover of the domestic trade cycle have a greater effect on the agricultural economic cycle than on the province's own domestic trade cycle. This may be one 
of the reasons for the large fluctuations in the agricultural economy before 2010. Compared with the late 1980s to the mid-1990s, the economic cycle of the provinces declined after 2010. The rise in the stabilizing effect of the domestic trade cycle, the spillover of the economic cycle, and the decline in the spatial spillover of the domestic trade cycle may have contributed to this change. In addition, after 2010, the impact of the spillover of the government spending cycle on the province's economic fluctuations has increased, and the possibility of government spending channels for triggering economic cycle synergy rise. In order to stabilize the domestic market's large fluctuations, it is necessary to further encourage the expansion of domestic trade scale, give play to the risk sharing function of domestic trade, and at the same time control the amplification effect of local government expenditures on agricultural economic fluctuations.

Acknowledgement: This study was funded by the Planning Fund on Humanities and Social Sciences of the Ministry of Education, China (13YJA790162)

\section{References}

[1] Cole S.A., Agricultural insurance and economic development, Ann. Rev. Econ., 2017, 9(1), 133-143.

[2] Zhang J.J., Zhao Q.L., Research on the interactive relationship between Chinese agricultural logistics and agricultural economy based on the time series data from 1991 to 2014, China Business Market, 2017, 31(1), 31-40.

[3] Jia X.L., Sun Z.L., Li X.D., Analysis on the characteristics of barley price fluctuation in China and its influencing factors, Chinese J. Agricult. Res. Reg. Plan., 2018, 39(1), 23-30.

[4] Tao Y., Shi J.M., Characteristics and influencing factors of the benefit of apple planting in China - An empirical analysis based on the apple planting benefit data from 1991 to 2014, Chinese J. Agricult. Res. Reg. Plan., 2017, 38(9), 167-173.

[5] Zhen S., Song Y., Zong Y.X., et al., Analysis of vegetable price fluctuation cycle and influencing factors in Hebei province Based on H-P filtering and VAR model analysis, Jiangsu Agricult. Sci., 2017, 45(19), 350-357.

[6] Gathorne-Hardy A., The sustainability of changes in agricultural technology: the carbon, economic and labour implications of mechanisation and synthetic fertilizer, Use. Ambio, 2016, 45(8), 1-10.
[7] Kong X., An empirical research of growth factors in low-carbon economy based on agricultural productivity tobit model, Chinese J. Agricult. Res. Reg. Plan., 2016, 37(10), 140-145.

[8] Wang B.B., Xiao H.F., Factors of fluctuation on China-Australia Llivestock products trade, J. China Agricult. Univ., 2016, 21(2), 160-167.

[9] Jiao J.,WX.Y., Guo L.H., et al., The development mode of agricultural economy in Hebei county from the cooperation network of Beijing-Tianjin- Hebei, Chinese J. Agricult. Res. Reg. Plan., 2017, 38(9), 181-189.

[10] Bai R., Chen L.L., Tian Z., The promotion of foreign direct investment to Jiangsu's agricultural economic development under the new economic normality and the countermeasures, Jiangsu Agricult. Sci., 2017, 45(10), 325-327.

[11] Su R.B., Chen L.Y., International synchronization of Chinese business cycle - the empirical analysis based on the nonlinear perspective, J. Shanxi Finan. Econ. Univ., 2016, 38(3), 1-11.

[12] Jin C.Y., Wang W.Q., An analysis of the correlation between Chinese fiscal policy effect and economic cycle fluctuation, From HowNet, J. Xi'an Jiaotong Univ. (Soc. Sci.), 2017, 37(3), 28-35.

[13] Zhang H.Y., Guo X.Y., Design and implementation of agricultural products mall based on personalized service, Autom. Instrum., 2016, (5), 80-82.

[14] Peng W., Huang Q., Research on complex information system evolution process, J. China Acad. Electr. Inform. Technol., 2017, 12(5), 475-480.

[15] Zhou Y., Deng Y.B., Simulation on the optimal profit consumption balancing model of agricultural products, Comp. Simul., 2016, 33(5), 344-347.

[16] Loiseau E., Aissani L., Le Feon S., Laurent F., Cerceau J., Sala S.et al., Territorial life cycle assessment (LCa): What exactly is it about? A proposal towards using a common terminology and a research agenda, J. Clean. Prod., 2018, 176, 474-485.

[17] Roca-Gonzalez J.L., López J.A.V., Martínez M.F., Raptor’s “Right Hunger" characterization to develop sustainable exclusion areas for wildlife at civil and military airports, Appl. Math. Nonlin. Sci., 2016, 1(2), 335-344.

[18] Fu H., Liu X., Research on the phenomenon of Chinese residents' spiritual contagion for the reuse of recycled water based on Sclat, Water, 2017, 9(84611).

[19] Peng W., Liu Z., Motahari-Nezhad M., Banisaeed M., Shahraki S., Beheshti M., A detailed study of oxy-fuel combustion of biomass in a circulating fluidized bed $(\mathrm{Cfb})$ combustor: evaluation of catalytic performance of metal nanoparticles (Al, Ni) for combustion eflciency improvement, Ener., 2016, 109, 11391147.

[20] Bortolan M.C., Rivero F., Non-autonomous perturbations of a non-classical non-autonomous parabolic equation with subcritical nonlinearity, Appl. Math. Nonlin. Sci., 2017, 2(1), 31-60.

[21] Jamatia S.K.S., Chaudhuri P.S., Species diversity and community characteristics of earthworms in managed and degraded tea plantations of Tripura, J. Envir. Biol., 2017, 38(6), 1349-1356. 